\title{
T2-mapping in normal volunteers compared to patients with edema reveals wide range of myocardial $\mathrm{T} 2$ in female volunteers
}

\author{
Ralf Wassmuth ${ }^{*}$, Andreas Greiser ${ }^{2}$, Jeanette Schulz-Menger ${ }^{1}$ \\ From 15th Annual SCMR Scientific Sessions \\ Orlando, FL, USA. 2-5 February 2012
}

\begin{abstract}
Summary
We applied T2 mapping in 72 volunteers compared to 15 patients with myocardial edema. T2 of myocardial edema was $70 \mathrm{~ms}$, whereas normal myocardium had a T2 of 55ms. However, female volunteers showed a wider range of myocardial T2 with overlap into values considered abnormal.
\end{abstract}

\section{Background}

T2-mapping has been proposed to overcome limitations of T2-weighted imaging of myocardial edema. We applied T2-mapping in normal volunteers to reveal the inter- and intra-individual homogeneity of myocardial $\mathrm{T} 2$ and to compare it to patients with myocardial edema.

\section{Methods}

We scanned 72 healthy volunteers $(36 \pm 13$ years, 18 females, heart rate $71 \pm 10 \mathrm{bpm}$ ) in a $1.5 \mathrm{~T}$ scanner. All had no cardiac disease and no signs of inflammation. We applied a FLASH and a SSFP-based T2-mapping sequence resulting in 3 single-shot images with echo times of 0,24 and $54 \mathrm{~ms}$ and a pixel size of $2.7 \times 2.1$ $\mathrm{mm}$ (slice thickness $8 \mathrm{~mm}$ ). Images were obtained in midventricular short axis and 4-chamber-view (4CV). We measured global and segmental T2 according to a 16-segment model. Contours were manually drawn on images by two independent observers and then copied to the map. 26 volunteers underwent additional mapping with reduced pixel size of $2.2 \times 1.8 \mathrm{~mm}$ and automatic motion correction. 6 volunteers were scanned twice on separate days. Results were compared to 15

${ }^{1}$ Cardiology, Helios Klinikum and Charite University Medicine Berlin, Berlin, Germany

Full list of author information is available at the end of the article patients with myocardial edema (12 infarctions, 1 myocarditis, 1 takotsubo, 1 sarcoidosis).

\section{Results}

We excluded 4 volunteers due to obvious pathologies. In patients myocardial edema had a T2 of $71 \pm 4 \mathrm{~ms}$ ( $p<0.001$ compared to volunteers). In volunteers mapping based on FLASH resulted in lower T2-values than SSFP $(52 \pm 4$ vs. $55 \pm 5 \mathrm{~ms} ; \mathrm{p}<0.001)$. T2 values were independent from heart rate, age or body weight. Apical septal segments had higher values than basal lateral segments in $4 \mathrm{CV}(64 \pm 8$ vs. $55 \pm 5 \mathrm{~ms}$ for SSFP, $\mathrm{p}<0.001)$. Women below 36 years had a $95 \%$ confidence interval of 43-86 ms based on SSFP mapping on 4CV images.

Mean intraobserver variability was $0.8 \pm 0.9 \mathrm{~ms}$ (correlation coefficient $r=0.99$ ), mean interobserver variability was $1.6 \pm 1.8 \mathrm{~ms}$ (correlation coefficient $\mathrm{r}=0.98$ ). Variability for repeated scans was $2.3 \pm 1.8 \mathrm{~ms}$. Improved spatial resolution and the applied motion correction did not significantly change the $\mathrm{T} 2$-measurements $(\mathrm{p}=0.3)$.

\section{Conclusions}

T2 mapping is feasible with low intra- and interobserver variability. T2 of myocardial edema was $70 \mathrm{~ms}$, whereas normal myocardium had a T2 of 55ms. However, female volunteers showed a wider range of myocardial T2 with overlap into values considered abnormal. This is most likely due to myocardial contamination with blood (T2 of about $180 \mathrm{~ms}$ ). Motion correction and spatial resolution needs to be improved before T2-mapping can widely be applied for exclusion of edema.

\section{Funding}

The scanner manufacturer provided a preliminary version of the mapping sequence based on the local 


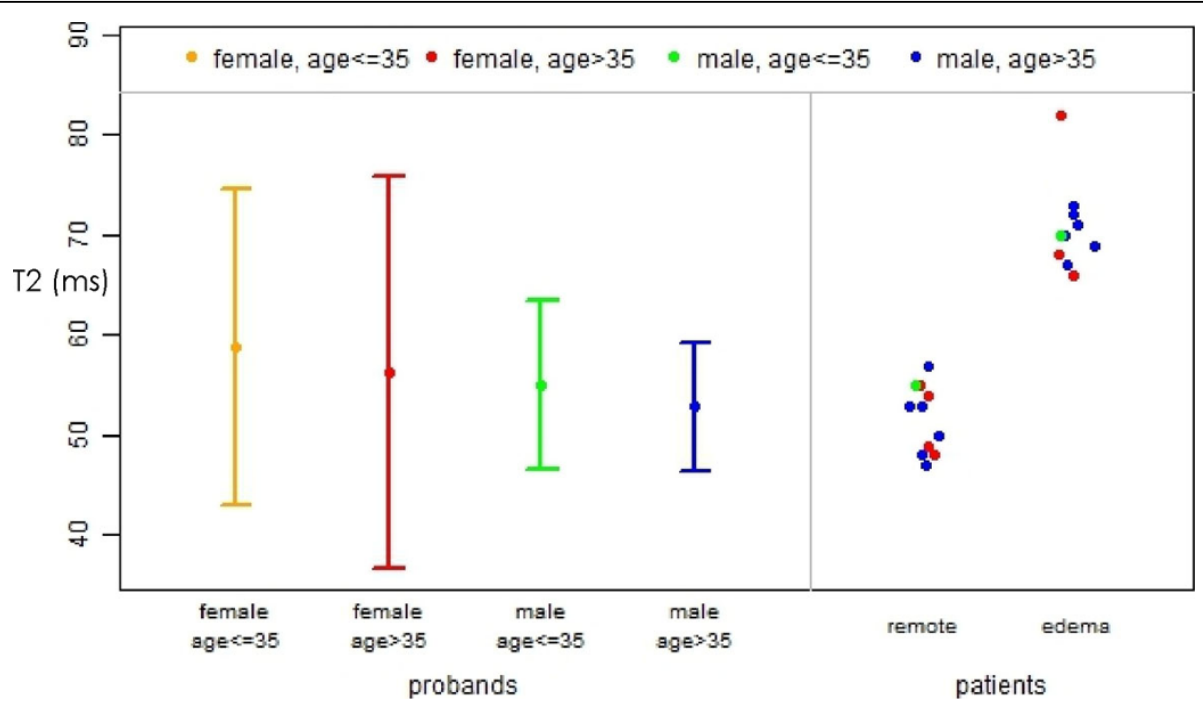

Figure 1 Mean myocardial T2 and 95\% Cl for female and male volunteers (left) compared to patients with edema (right).

research agreement. Funding was provided by the university.

\section{Author details}

${ }^{1}$ Cardiology, Helios Klinikum and Charite University Medicine Berlin, Berlin,

Germany. ${ }^{2}$ Imaging and IT Division, Siemens Healthcare, Erlangen, Germany.

Published: 1 February 2012

doi:10.1186/1532-429X-14-S1-081

Cite this article as: Wassmuth et al:: T2-mapping in normal volunteers

compared to patients with edema reveals wide range of myocardial T2

in female volunteers. Journal of Cardiovascular Magnetic Resonance 2012

14(Suppl 1):081.

Submit your next manuscript to BioMed Central and take full advantage of:

- Convenient online submission

- Thorough peer review

- No space constraints or color figure charges

- Immediate publication on acceptance

- Inclusion in PubMed, CAS, Scopus and Google Scholar

- Research which is freely available for redistribution

Submit your manuscript at www.biomedcentral.com/submit 